\title{
Correction to: Women's Experience of Orgasm During Intercourse: Question Semantics Affect Women's Reports and Men's Estimates of Orgasm Occurrence
}

\author{
Talia Shirazi $^{1,3} \cdot$ Kaytlin J. Renfro $^{1} \cdot$ Elisabeth Lloyd $^{2} \cdot$ Kim Wallen $^{1}$
}

Published online: 10 November 2017

(C) Springer Science+Business Media, LLC 2017

\section{Correction to: Arch Sex Behav \\ https://doi.org/10.1007//10508-017-1102-6}

The name of coauthor Kaytlin J. Renfro has been corrected since this article was originally published.

Talia Shirazi

talia.shirazi@gmail.com

1 Department of Psychology, Emory University, Atlanta, GA, USA

2 Department of History and Philosophy of Science and Medicine, Indiana University, Bloomington, IN, USA

3 Department of Anthropology, Pennsylvania State University, University Park, State College, PA 16802, USA 